\section{LMJ Status Report}

\author{
Michel L. André \\ Centre d'Etudes de Bruyères-le-Chatel, France
}

\author{
Michel Decroisette \\ Centre d'Etudes de Limeil-Valenton, France
}

The Laser Megajoule Project (LMJ) is a major component of the French stockpile stewardship programme. An evaluation of the feasibility (avant projet sommaire) describing the technical, financial and timescale aspects of the project was completed in 1994. In 1995, the French

Ministry of Defence authorized the project and preparation of the advanced design report. The CEA laboratory, CESTA, near the city of Bordeaux, has been chosen for the project site.

The goal of the project is to build a solid state laser capable of delivering on target an energy of $1.8 \mathrm{MJ}$ and a power of 600 TW at the third harmonic $(0.35 \mu \mathrm{m})$ of the laser wavelength $(1.05 \mu \mathrm{m})$, in order to reach DT ignition and obtain significant gain from X-ray driven targets. The main specifications are listed in table 1.

In order to reach these specifications, simulation codes and the experience acquired on Phebus have demonstrated that a 240 beamline laser, each beamline having an area of $40 \times 40 \mathrm{~cm}^{2}$, is necessary. This evaluation took into account the desire for maintaining performances on a

Table 1 Main specifications of the LMJ project
$\begin{array}{ll}\text { Energy } & >1.8 \mathrm{MJ} \\ \text { Power } & >500 \mathrm{TW} \\ \text { Wavelength } & 0.35 \mu \mathrm{m} \\ \text { Pointing accuracy } & 50 \mu \mathrm{m} \\ \text { Energy stability } & 7 \% \mathrm{rms} \\ \text { Focusing capability } & 98 \% \text { energy in } 0.6 \mathrm{~mm} \\ \text { Shot rate } & 30 \text { shots / year full power } \\ & 600 \text { shots / year total }\end{array}$

routine basis and for a long lifetime for the facility ( 30 years). Table 2 shows the definition of the main structure. The general design of each laser beamline is presented in figure 1 . Four passes of the beam in the laser cavity are obtained via the socalled 'L-Turn' concept, in which the pulses cross the amplifiers four times due to a passive optical system placed in the transport spatial filter.

It is very similar to the beam structure of the National Ignition Facility (NIF) project developed by the US Lawrence Livermore National Laboratory.

The 30 bundles of eight beamlets each will be arranged in an in-line building designed to shorten the beam transport as much as possible. This arrangement is

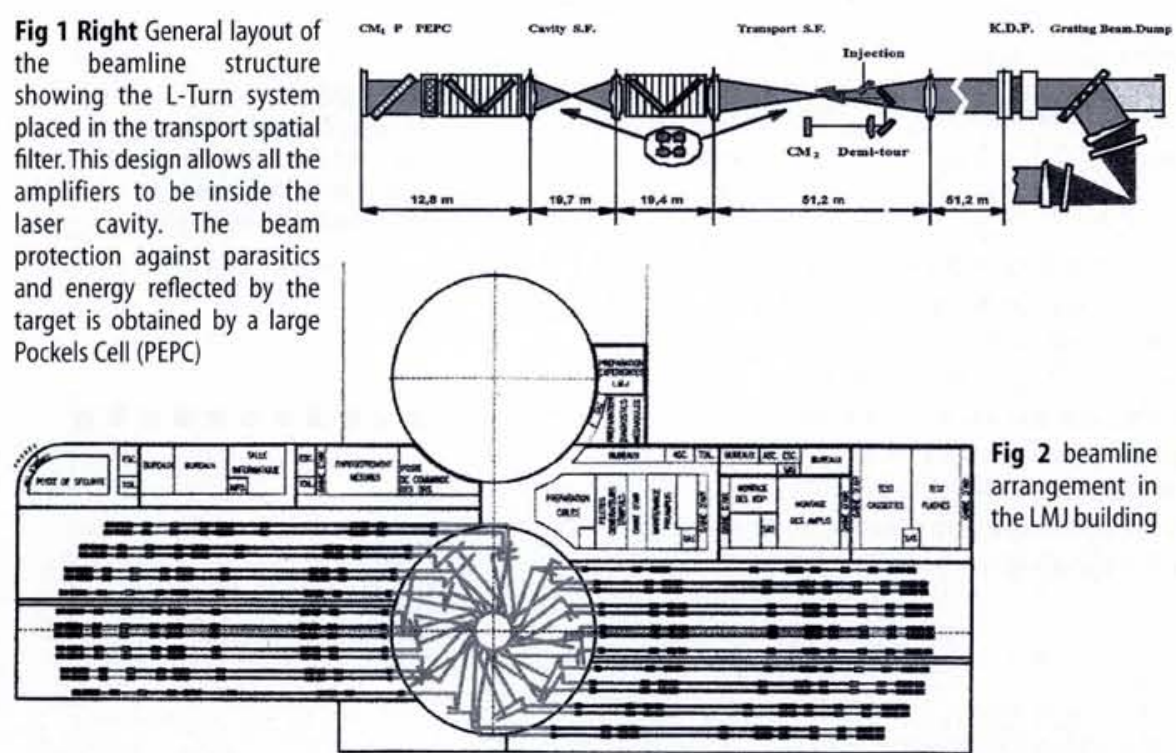

shown in figure 2.

The focusing of the beams on target is performed using transmission gratings which have two functions: filtering of the unconverted light and focusing the $0.35 \mu \mathrm{m}$ useful wavelength. The arrangement of the focusing on target has been designed in order to be as flexible as possible. Particularly the possibility of using indirect or direct configuration has been taken into account.

The required technological developments are conducted in close collaboration with the Lawrence Livermore National Laboratory through an official agreement between the CEA in France and the Department of Energy in the US. This collaboration provides peer review of critical development and lowers the total technology investment costs.

In order to validate the LMJ technology base an eight beam prototype, Ligne d'Intégration Laser (LIL), will be constructed in advance of the LMJ. This prototype will also serve as a test bed for establishing construction, activation and maintenance procedures and training future LMJ personnel. The building that will house LIL has already been built. Four out of eight LIL beams will be operational by the beginning of 2001, and target experiments at the $60 \mathrm{~kJ}$ level will start in January 2002.

The LMJ itself will be completed in two phases. The building construction will be completed in 2003 , to allow activation of phase 1 : 80 beamlines to begin the same year. Completion of phase I and experiments at the $600 \mathrm{~kJ}$ level are planned for 2006. Completion of phase II with the full 240 beamlines is currently planned for 2010.

Our main efforts are devoted at the moment to finalizing the technological developments. Those developments cover all aspects of the laser, controls and experience domains.

In concluding this overview of the status of the LMJ project, all the technical aspects have been taken into account, and the LIL will soon demonstrate LMJ level performance giving us confidence that we will obtain the ambitious objectives of the LMJ.

\begin{tabular}{|c|c|}
\hline Number of beamlets & 240 \\
\hline Beam size & $40 \times 40 \mathrm{~cm}^{2}$ \\
\hline Beam arrangement & $4 \times 2$ \\
\hline Target chamber diameter & 10 meters \\
\hline \multicolumn{2}{|c|}{ Focusing arrangement vertical axis } \\
\hline & 32 beamlets \\
\hline & 44 beamlets \\
\hline & 44 beamlets \\
\hline \multicolumn{2}{|c|}{$\begin{array}{l}\text { Also An option for a second target chamber exists. } \\
\text { Beam smoothing is required }\end{array}$} \\
\hline
\end{tabular}

